\title{
Specialist Physicians Providing Primary Care Services in Colorado
}

\author{
George E. Fryer, Jr, PhD, Rachel Consoli, MD, PH, Thomas J. Miyoshi, MSW, \\ Susan M. Dovey, PhD, Robert L. Phillips, Jr, MD, MSPH, and Larry A. Green, MD
}

Background: There is general consensus that the size of the US physician workforce now exceeds the health care needs of the American public. There is a greater proportion of specialists than primary care physicians, a specialty mix different from that of most other developed countries.

Methods: The Colorado Board of Medical Examiners sent a one-page questionnaire to all physicians licensed to practice in the state. It contained the question: "How many hours in the last week did you provide primary care services, defined as either preventive care, routine physical exams, or treatment of common ailments?" The responses of physicians who reported non-primary-care medical specialties were analyzed with respect to their personal and practice characteristics.

Results: Just under half $(\mathbf{4 6 . 5 \% )}$ of the 2745 specialist respondents reported having provided primary care services. As a group, however, $27.9 \%$ of specialist physicians' direct patient care time was devoted to primary care activities. The amount of primary care services being provided was greater among those not board-certified in their specialties, osteopathic physicians, and specialists spending less time in direct patient care.

Conclusion: Additional evaluation is needed with a more comprehensive definition of primary care than used in this article, which includes important but difficult-to-measure elements, such as the integration of services, a sustained partnership with patients, and practice in the context of family and community. To the extent possible, this definition should not rely on physician self-definition of which examinations are routine and which ailments are common. However, the contribution of specialists should be considered in future primary care needs assessments, and specialists who experience low demand for their particular specialties may be especially inclined to provide primary care services. ( $\mathrm{J}$ Am Board Fam Pract 2004;17:81-90.)

From 1959 to 1970,5 reports were commissioned and published amid growing concern that a physician shortage had developed in the United States. ${ }^{1-5}$ All 5 reports called for expansion of the physician workforce. With a massive infusion of public funds, 40 new allopathic medical schools were begun and enrollment doubled from 1962 to $1982 .^{6}$ But the resultant growth was remarkably

Submitted, revised, 28 August 2003.

From the Robert Graham Center for Policy Studies in Family Practice and Primary Care, American Academy of Family Physicians, Washington, DC (GEF, RC, SMD, RLP, LAG) and the Colorado Area Health Education Center Program, University of Colorado Health Sciences Center at Fitzsimons, Aurora (TJM). Address correspondence to: George E. Fryer, Jr., PhD, Robert Graham Center, American Academy of Family Physicians, 1350 Connecticut Avenue, N.W., Suite 950, Washington, D.C. 20036 (e-mail: efryer@aafp.org).

The information and opinions contained in research from the Graham Center do not necessarily reflect the views or policy of the American Academy of Family Physicians. greater in specialty medicine than among general medicine. ${ }^{7}$ Thus, even with the possible excess of physicians that had been produced, access to primary medical care remained inadequate for millions of Americans, particularly the residents of sparsely settled rural regions. ${ }^{8}$ Enactment in 1976 of the Health Professions Educational Assistance Act shifted national workforce objectives from increasing the aggregate supply of doctors to producing primary care physicians amenable to practice in needy areas. ${ }^{9}$ The Federal government invested in the National Health Service Corps, Area Health Education Centers, and Title VII activities in primary care departments of both allopathic and osteopathic schools of medicine to implement the new policy. But progress was slow, prompting the Council on Graduate Medical Education (COGME) in 1992 to recommend adoption of a 50:50 generalist/specialist mix as a national goal, 
and that first-year residency positions be capped at $110 \%$ of the number of graduates of US medical schools each year. ${ }^{10}$

Developed countries with successful health care systems typically rely heavily on the services of their generalist physicians. Yet, little is known about the extent to which medical specialists in the United States attend to the primary care needs of patients. This knowledge has implications for physician workforce policy. The Institute of Medicine (IOM), in calling for a comprehensive national study of primary care rendered by specialists, reported that specialists respond to the lack of demand for their services, when in oversupply, by providing primary care. ${ }^{11}$

The first major examination of primary care activities of specialists was done in the mid-1970s. At that time, approximately $20 \%$ of all Americans received on-going care for most of their health problems from specialists. ${ }^{12}$ Since then, some analyses have been conducted with large national data sets to address this issue, ${ }^{13-16}$ but, to our knowledge, no research has directly measured the amount of primary care provided by physicians of all nongeneralist medical specialties or identified related factors.

The objectives of this study were (1) to analyze workforce and workload data from one state, Colorado, (2) to determine the proportion of specialists who report providing primary care services and the amount they provide, and (3) to measure the associations of their personal, professional, and practice characteristics with the provision of primary care services, and (4) to estimate the extent to which specialists provide primary care services to compensate for lack of demand for their specialized medical services.

\section{Methods}

\section{Data Collection}

The Colorado Board of Medical Examiners mailed a one-page questionnaire to all physicians licensed to practice in the state. The survey form was enclosed in an envelope along with materials required for license renewal in 2001. Questionnaires contained guarantees of confidentiality of response and stated that the data were being collected for purposes of manpower research. Respondents were instructed to return completed surveys along with their licensure documents.

\section{Definition of Primary Care Services}

For the purposes of this study, primary care services were determined from the survey item "How many hours in the last week did you provide primary care services, defined as either preventive care, routine physical exams, or treatment of common ailments?" These services are basic elements of primary care practice and are most commonly performed by generalist physicians. But the simple provision of these services does not constitute primary care, defined by the Institute of Medicine as:

The provision of integrated, accessible health care services by clinicians who are accountable for addressing a large majority of personal health care needs, developing a sustained partnership with patients, and practicing in the context of family and community. ${ }^{11}$

But although the procedure-based study definition does not encompass all aspects of primary care, it has been used in nationally representative physician surveys ${ }^{17}$ and consists of measurable categories.

\section{Study Variables}

Two dependent variables were used in assessing the primary care contribution of Colorado specialists: (1) whether the specialist provided any primary care services at all and (2) what proportion of direct patient care time was spent providing primary care services. We assessed the association of personal, professional and practice variables with the pattern of providing primary care services among specialist physicians:

\section{Personal variables}

a. Age (5 age groups)

b. Sex (male vs female)

c. Race/ethnicity (4 groups with 35 respondents or more)

2. Professional variables
a. Type of degree (MD vs DO)
b. Specialty board certification (yes vs no)
c. Primary medical specialty
d. Secondary medical specialty

\section{Practice variables}

a. Practice setting (office/clinic/treatment center, hospital, nursing home, teaching institution) 
b. Practice type (solo, partnership/group, state salary/contract, municipal salary/contract, other contract, medical school)

c. Primary practice site (rural, non-metropolitan statistical area county versus urban, metropolitan statistical area county)

d. Relocated practice in last 2 years (yes versus no)

e. Provide care to Medicare, Medicaid patients (yes versus no)

f. Accepting any new, new Medicare, new Medicaid patients (yes versus no)

g. Hours per week in direct patient care

\section{Study Participants}

Among responding physicians, criteria for inclusion in study analyses were:

1. primary medical specialty other than family medicine, general practice, general internal medicine, or general pediatrics.

2. not employed by the federal government.

3. providing direct patient care at least 20 hours per week.

4. not a resident or clinical fellow.

5. primary practice site located in the state of Colorado.

6. a survey response to the item: 'How many hours in the last week did you provide primary care services, defined as either preventive care, routine physical exams, or treatment of common ailments?'

\section{Results}

If data were missing for any of these criteria, the physician was excluded from study analyses. The Board of Medical Examiners does not determine the number of physicians to whom they mail who have Colorado addresses and does not ascertain which physicians are involved in direct patient care. Consequently, the actual rate of survey response cannot be determined. The 2745 respondents who met all study criteria constitute $50.9 \%$ of the number of physicians with characteristics 1 to 5 above in the American Medical Association Masterfile for Colorado mid-year in 2000. This response rate is much lower than the one similarly calculated for the survey done in conjunction with 1995 relicensure. The $82.7 \%$ response attained in 1995 was found to be very representative of physicians prac- ticing in the state according to the American Medical Association Physician Masterfile. ${ }^{18}$ Inclusion criteria for this study were much more stringent than in 1995, requiring more information, some of which had not been requested by previous surveys. Of 3772 Colorado specialist respondents to the survey, 496 did not report activity data adequate to compute time in primary care, 646 were spending fewer than 20 hours in direct patient care, and 145 were federally employed. These exclusion criteria counts are not mutually exclusive. Nevertheless, respondents were generally representative of direct patient care specialist physicians on the 2000 Masterfile. Among survey respondent specialists, 9.5\% were practicing in a rural county (vs. $9.4 \%$ in the Masterfile), $19.6 \%$ were female (vs $19.2 \%$ in the Masterfile), and $4.2 \%$ were DOs (vs $3.8 \%$ in the Masterfile).

\section{The Primary Care Contribution by Specialists}

Most specialists (53.5\%) reported that none of their time during the week preceding survey response involved primary care activity. An average of $27.9 \%$ of the direct patient care time of specialists was spent providing primary care services. This accounts for 12.5 hours weekly per nongeneralist physician. Approximately one third (34.0\%) of specialists devoted at least one fourth of their clinical time to providing primary care services, and $26.0 \%$ spent half or more of their direct patient care time. A substantial number $(398,14.5 \%)$ reported spending as much time in primary care activity the week before completing the survey as they average weekly in direct patient care.

\section{The Influence of Physician Characteristics}

The small number of minority physicians, particularly those under-represented in the medical profession, precluded meaningful comparisons involving race and ethnicity (Table 1 ). Female specialists were more likely to provide primary care services than their male counterparts, as were the youngest (under 35, 57.4\%) and oldest (over 64, 58.3\%). Professional credentials were also associated with both the proportion of specialists providing primary care services and the amount they were providing. Osteopathic specialists provided significantly more primary care services than MDs, and specialists who were not board-certified provided more primary care services than those who were certified. Practice characteristics were also related 


\title{
2001 PHYSICIAN SURVEY
}

\author{
3-21-01
}

This surrey is a collaborative projest, for manpower rese arch parposes, among the Colorado Board of Medieal Exam iners, and the Unirersity of Colorado Health Seiences Center. Your cooperation in completing and refurning this questionn aire is needed and appreciated. Indiyidual responses are com plefely confide ntial. Please return the que stionnaire with your ficense renewat materials. Thank you.

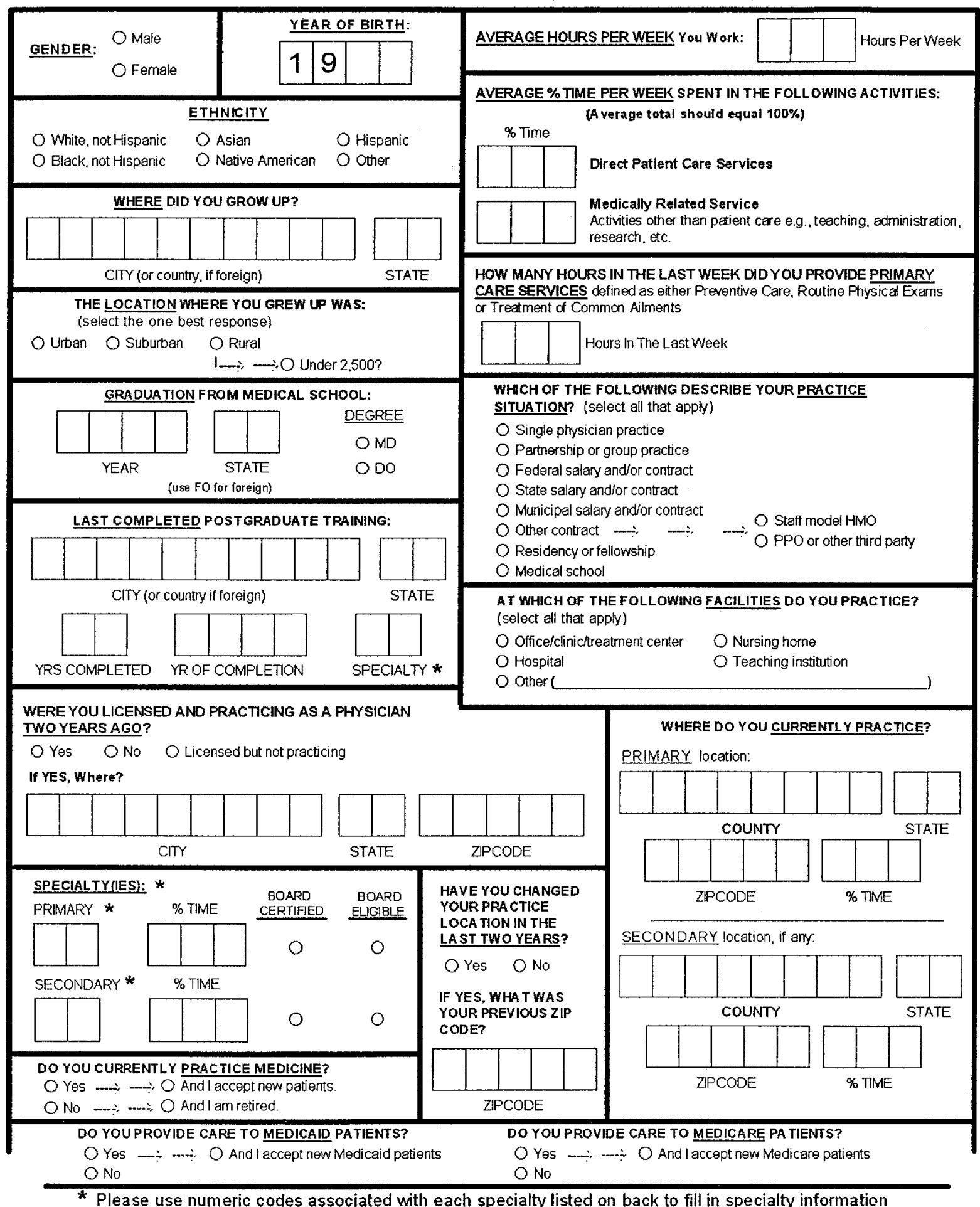

Figure 1. Survey. 
Table 1. Provision of Primary Care Services by Personal, Educational, and Medical Practice Characteristics of Colorado Specialist Physicians

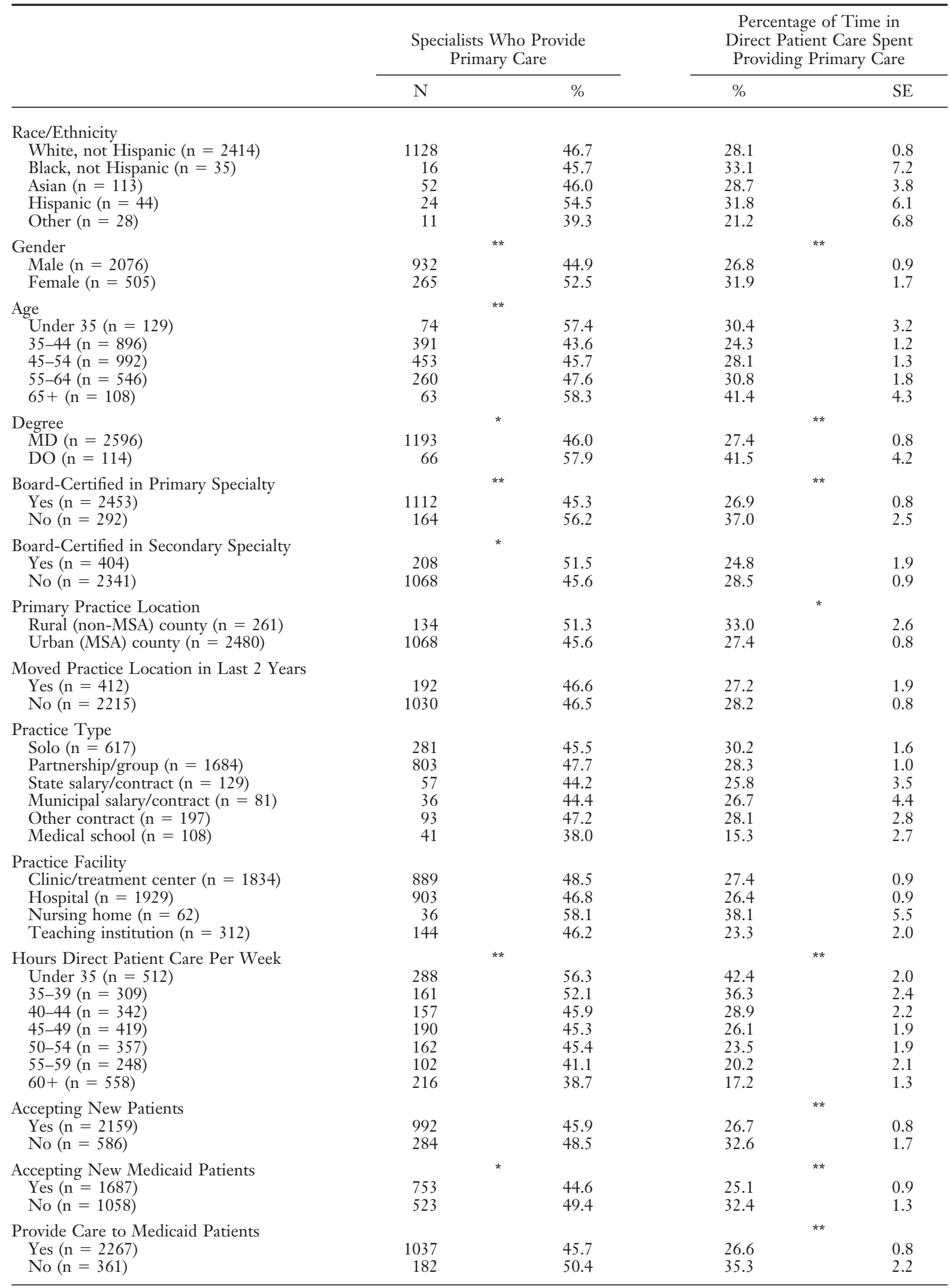




\begin{tabular}{|c|c|c|c|c|}
\hline & \multicolumn{2}{|c|}{$\begin{array}{c}\text { Specialists Who Provide } \\
\text { Primary Care }\end{array}$} & \multicolumn{2}{|c|}{$\begin{array}{l}\text { Percentage of Time in } \\
\text { Direct Patient Care Spent } \\
\text { Providing Primary Care }\end{array}$} \\
\hline & $\mathrm{N}$ & $\%$ & $\%$ & SE \\
\hline Accepting New Medicare Patients & & & & \\
\hline Yes $(n=1854)$ & 840 & 45.3 & 26.0 & 0.9 \\
\hline No $(\mathrm{n}=891)$ & 436 & 48.9 & 32.0 & 1.4 \\
\hline \multicolumn{5}{|l|}{ Provide Care to Medicare Patients } \\
\hline Yes $(\mathrm{n}=2330)$ & 1081 & 46.4 & 27.4 & 0.8 \\
\hline No $(\mathrm{n}=205)$ & 93 & 45.4 & 32.0 & 2.4 \\
\hline
\end{tabular}

Note: Respondents could report more than one practice type and facility.

${ }^{*} P<.05$ for $\chi^{2}$ test and analysis of variance.

${ }^{* *} P<.01$ for $\chi^{2}$ test and analysis of variance.

to the provision of primary care services. Specialists with practices in rural areas and those spending less time in clinical care were more involved in primary care activity. Providers of primary care services actually spent less time in direct patient care than did other specialists, even with primary care service time included in their total for patient care. Unlike the relationship of age with time involved in primary care activity, the inverse association of hours spent in direct patient care with primary care service was found to be linear. Osteopathic specialists (7.1\%), non-board-certified physicians (15.3\%), and those serving rural communities (13.1\%) were over-represented among the 308 specialists, who spent as much time providing primary care services the week before the survey as they do in direct patient care weekly. Specialists who were not accepting any new patients or patients enrolled in either Medicaid or Medicare were providing more primary care services than physicians who were adding patients to their caseloads.

\section{The Role of Medical Specialty}

The primary and secondary specialties of nongeneralists were the practice characteristics most influential of their tendency to provide primary care services (Table 2). Among the most numerous primary specialties, physicians in emergency medicine and obstetrics/gynecology were most involved in primary care activity. Only $18.1 \%$ (497 of 2745) of all specialists reported a secondary specialty. The majority of those $(60.2 \%, 299$ of 497) were primary care specialties. General internal medicine accounted for more (207) than any other specialty. These specialists with secondary specialties, especially if these were primary care specialties, were more active providers of primary care services than were other specialists. Most were board-certified in their secondary specialty $(81.3 \%, 404$ of 497$)$. Of the 308 specialists who spent roughly all their direct patient care time providing primary care services during a reporting week, $28.4 \%$ were emergency medicine specialists.

\section{Discussion}

\section{Potential Effect of the Primary Care Contribution of Colorado Specialists on Access}

Most specialists in Colorado do not provide primary care services to their patients. In aggregate, however, their contribution is considerable. Of the 47.9 hours, on average, that specialists spend in direct patient care each week, 12.5 were devoted to primary care activity. Applied to all specialists in the state, including survey nonrespondents, this constitutes 1507.1 primary care FTE from specialist physicians, assuming equal time for specialists and primary care physicians in direct patient care each week. In 2000, there were 2992 nonfederal direct patient care generalist doctors in Colorado not in residency or a clinical fellowship. Thus, we estimate that specialists are providing $33.5 \%$ of primary care services in the state, extending total physician time in primary care activity by $50.9 \%$. The latter estimate assumes that generalist physicians would not have provided any of the primary care services that were provided by specialists.

\section{The Association of Time Spent Providing Specialized vs Primary Care Services}

Specialists providing primary care services were less likely to be board certified in their primary spe- 


\begin{tabular}{|c|c|c|c|c|}
\hline & \multicolumn{2}{|c|}{$\begin{array}{c}\text { Specialists Who Provide } \\
\text { Primary Care }\end{array}$} & \multicolumn{2}{|c|}{$\begin{array}{c}\text { Percent of Time in Direct } \\
\text { Patient Care Spent Providing } \\
\text { Primary Care }\end{array}$} \\
\hline & $\mathrm{N}$ & $\%$ & $\%$ & SE \\
\hline $\begin{array}{l}\text { Primary Medical Specialty } \\
\text { Allergy/Immunology }(\mathrm{n}=39) \\
\text { Anesthesiology }(\mathrm{n}=294) \\
\text { Cardiology }(\mathrm{n}=88) \\
\text { Dermatology }(\mathrm{n}=64) \\
\text { Emergency Medicine }(\mathrm{n}=252) \\
\text { Endocrinology/Diabetes/Metabolism }(\mathrm{n}=23) \\
\text { Gastroenterology }(\mathrm{n}=56) \\
\text { Geriatrics }(\mathrm{n}=23) \\
\text { Infectious Disease }(\mathrm{n}=25) \\
\text { Nephrology }(\mathrm{n}=29) \\
\text { Neurological Surgery }(\mathrm{n}=24) \\
\text { Neurology }(\mathrm{n}=62) \\
\text { Obstetrics/Gynecology }(\mathrm{n}=267) \\
\text { Oncology }(\mathrm{n}=62) \\
\text { Ophthalmology }(\mathrm{n}=147) \\
\text { Orthopedics }(\mathrm{n}=160) \\
\text { Otolaryngology }(\mathrm{n}=65) \\
\text { Pathology }(\mathrm{n}=85) \\
\text { Physical Medicine/Rehabilitation }(\mathrm{n}=69) \\
\text { Plastic Surgery }(\mathrm{n}=51) \\
\text { Preventive Medicine }(\mathrm{n}=21) \\
\text { Psychiatry }(\mathrm{n}=297) \\
\text { Radiology }(\mathrm{n}=183) \\
\text { Surgery }(\mathrm{n}=153) \\
\text { Urology }(\mathrm{n}=61) \\
\text { Other }(\mathrm{n}=145)\end{array}$ & $\begin{array}{r}20 \\
51 \\
37 \\
29 \\
210 \\
13 \\
19 \\
17 \\
18 \\
18 \\
4 \\
8 \\
247 \\
30 \\
89 \\
57 \\
36 \\
15 \\
29 \\
15 \\
19 \\
105 \\
38 \\
53 \\
23 \\
76\end{array}$ & $\begin{array}{l}51.3 \\
17.3 \\
42.0 \\
45.3 \\
83.3 \\
56.5 \\
33.9 \\
73.9 \\
72.0 \\
62.1 \\
16.7 \\
12.9 \\
92.5 \\
48.4 \\
60.5 \\
35.6 \\
55.4 \\
17.6 \\
42.0 \\
29.4 \\
90.5 \\
35.4 \\
20.8 \\
34.6 \\
37.7 \\
52.4\end{array}$ & $\begin{array}{r}28.3 \\
11.8 \\
20.2 \\
30.5 \\
66.6 \\
19.3 \\
11.9 \\
70.1 \\
25.3 \\
9.2 \\
11.6 \\
7.1 \\
46.4 \\
25.8 \\
47.5 \\
18.9 \\
26.3 \\
15.4 \\
26.0 \\
13.4 \\
74.8 \\
24.5 \\
13.0 \\
14.2 \\
12.9 \\
24.9\end{array}$ & $\begin{array}{l}6.3 \\
1.8 \\
3.9 \\
5.2 \\
2.5 \\
6.5 \\
3.6 \\
9.1 \\
6.4 \\
2.2 \\
6.2 \\
2.8 \\
1.8 \\
5.0 \\
3.6 \\
2.7 \\
4.5 \\
3.9 \\
4.8 \\
4.2 \\
7.8 \\
2.3 \\
2.3 \\
2.5 \\
3.5 \\
3.1\end{array}$ \\
\hline $\begin{array}{l}\text { Secondary Medical Specialty } \\
\text { Family Practice }(\mathrm{n}=39) \\
\text { Internal Medicine }(\mathrm{n}=207) \\
\text { Pediatrics }(\mathrm{n}=47) \\
\text { Other }(\mathrm{n}=198) \\
\text { None }(\mathrm{n}=2248)\end{array}$ & $\begin{array}{r}29 \\
120 \\
16 \\
90 \\
1016\end{array}$ & $\begin{array}{l}74.4 \\
58.0 \\
34.0 \\
45.5 \\
45.2\end{array}$ & $\begin{array}{l}62.5 \\
25.5 \\
17.9 \\
23.1 \\
28.1\end{array}$ & $\begin{array}{l}7.2 \\
2.6 \\
5.0 \\
2.6 \\
0.8\end{array}$ \\
\hline
\end{tabular}

cialty and spent less time in direct patient care than other specialists. These findings suggest that providing primary care services may be both a response to difficulty experienced in competing with boardcertified providers for patients and an indication of their clinical availability beyond that required for specialty services. Primary care service-providing specialists spent less time each week with patients than other specialists, even with their clinical activity in primary care taken into account. The average percentage of clinical time in primary care activity was $27.9 \%$ for all specialists, but $58.8 \%$ for just the $47.5 \%$ (1276) who provide any primary care services. Thus, specialists who provide no primary care services average 48.3 hours in specialty care per week vs. 18.9 hours in specialty care (and 26.8 hours primary care activity) by primary care service-providing specialists.

There was no provision in the survey to determine whether this phenomenon reflected professional choice or a need to fill available clinical time for which there was no demand for specialized medical services. But the fact that non-board-certified specialists, a less-credentialed group perhaps disadvantaged in the competition for patients with specialty needs, was particularly involved in primary care services does suggest an effort to create a more robust caseload in the face of limited demand for their specialty services. This finding is consistent with the IOM prediction for specialist behavior in a labor market in which their number exceeds the need of the public for the services of their specialty.

\section{The Special Case of Certain Specialties}

Many of the specialties that provide a lot of primary care services are understandably required to conduct physical examinations, an integral activity to our definition of primary care services. This was the case with emergency medicine, obstetrics/gynecology, and ophthalmology. Similarly, the clinical focus of preventive medicine physicians is also a 
mainstay of the definition of primary care services. Although the small number of members of certain specialties made their assessment difficult, the specialty mix of specialist physicians was a major determinant of their overall contribution of primary care services. The large majority of emergency medicine physicians provided some primary care services; on average, it consumed approximately two thirds of their clinical time. This is probably attributable in part to continued reliance on the emergency department by some Colorado patients for nonurgent ambulatory care, as well as the fact that the examination of patients is a basic component of emergency department services. It also suggests that the need for some primary care services may be incidental to emergency care and that the legal requirement in emergency departments of general hospitals to serve those who visit, regardless of reason/urgency, sometimes results in the provision of primary care services.

There remains some disagreement about classifying obstetrics/gynecology (OB/Gyn) as a primary care specialty. There were 267 responses from OB/ Gyns, just 20 (7.5\%) of whom reported not providing any primary care services. OB/Gyns average almost half $(46.4 \%)$ of their time in primary care activity, somewhat less than emergency medicine physicians. Although they have not been considered primary care physicians in our analyses, OB/ Gyns are classified as such by the American Medical Association and the Bureau of Health Professions in Primary Care Health Personnel Shortage Area (PCHPSA) designation. For analyses of the physician workforce, their classification has huge implications for results.

Most specialists did not report a secondary specialty, although those who did were often boardcertified. Primary care accounted for most secondary specialties $(60.2 \%, 299$ of 497). Thus, more than one in 10 Colorado specialists reported a secondary specialty in primary care. General internal medicine was the most frequently reported secondary specialty. ${ }^{207}$ But family practice was the only generalist secondary specialty characterized by substantially greater provision of primary care services than among other specialist physicians $(62.5 \%$ of their direct patient care time).

\section{Study Limitations}

The survey response rate could not be determined with precision for reasons previously explained in
Methods. This is reason for caution in the interpretation of our findings. Physicians were asked the number of hours they work in an average week, but to reduce bias associated with recall, they were asked the number of hours they spent in primary care activity just during the last week. Our study was cross-sectional, giving no indication of changes occurring over time.

The proportion of primary care services provided in Colorado by specialist physicians is probably somewhat underestimated. Those involved in direct patient care for fewer than 20 hours per week were excluded from study analyses, although they almost certainly provide some primary care services not taken into account in our calculations. In addition, not all the clinical time of generalist physicians was being spent in primary care activities (family physicians, $86.6 \%$; general practitioners, $84.5 \%$; general internists, $71.1 \%$; and general pediatricians, $79.4 \%$ ).

Finally, the definition of primary care services, although typically used elsewhere, ${ }^{17}$ lacks major elements of the widely used definition developed by the Institute of Medicine. Our use of this purely procedural definition excludes elements of primary care such as comprehensiveness, undifferentiated presentation, continuity, and coordination.

\section{Physician Workforce Policy Implications}

Medical specialists in Colorado provide a substantial amount of primary care services. A comprehensive systematic literature review showed the quality of care by specialists in their specialty domain exceeds that of care by generalist physicians. ${ }^{19}$ But recent research has revealed that the care specialists provide outside their field of specialization is of lower quality than that provided by primary care physicians. ${ }^{20}$ Thus, the finding of this study that specialists provide a considerable amount of primary care services raises important research questions relevant to the current debate of quality in health care.

The operational definition of primary care services in this study was procedure-based and devoid of important, less measurable elements of the Institute of Medicine's definition of primary care. ${ }^{11}$ The integration of health services on which good primary care is founded entails that health care be comprehensive, coordinated, and continuous. This requires a sustained partnership with patients served in the context of their family and commu- 
nity. The inability of generalist physicians in today's health system to assure the delivery of services so characterized has caused them to question the quality of the care they provide, a major source of dissatisfaction with their professional careers. ${ }^{21}$ Those most disaffected cite system-imposed difficulty in communicating with specialists, spending adequate time with patients, having the freedom to make good clinical decisions, and maintaining continuing relationships with patients.

Specialists considerably outnumber generalists in this country but account for fewer than half of all office visits annually, ${ }^{22}$ and only $24 \%$ of Americans perceive a need for specialized medical care in a year. ${ }^{23}$ In this environment, specialists may be tempted to venture into the primary care domain, a domain less characterized by the traditional features of good primary care, one in which they are less frustrated professionally than are generalist physicians. The American public has demonstrated its satisfaction with primary care that is continuous, on-going, and received from a single provider. ${ }^{24}$ In 1996, 93\% of participants in the Medical Expenditure Panel Survey (MEPS) who identified a single provider as their usual source of care identified a primary care physician. Only about 3\% were dissatisfied with their usual source, on whom they relied for help with new health problems, preventive care, and referrals to other health professionals when needed. ${ }^{25}$ Primary care physicians are being challenged to differentiate their contribution from that of other providers in a health care system in which they perceive their services as undervalued. ${ }^{26}$

The observations of this study may be seen as the product of failure of the national policy objective of reducing the proportion of the physician workforce composed of specialists. ${ }^{11}$ More recently, researchers have cautioned that the generalist physician workforce may soon exceed the public's need for its services, and that additional specialists are needed. ${ }^{27}$ Our results suggest that specialists may be in oversupply, a phenomenon somewhat obscured by their participation in primary care activity. In any event, specialist performance of primary care tasks is particularly complicating to increasingly important assessments of need.

\section{Conclusion}

From our study of the state of Colorado alone, the specialist physician primary care contribution seems substantial enough to warrant provision in primary health care needs assessments and physician workforce analyses. There is considerable variation in the amount of primary care services provided by medical specialists, some of which may relate to the inability of some to compete for delivery of specialty care or may simply be a logical product of an oversupply of medical specialists. Research is needed to determine whether the primary care services provided by specialists differs in quality or satisfaction to patients and whether these services help ameliorate accessibility to care.

\section{References}

1. Bane F. Physicians for a growing America: Report of the Surgeon General's consultant group on medical education. Publication No . R709. Washington DC: US Public Health Service, Department of Health, Education, and Welfare; 1959.

2. Coggershall LT. Planning for medical progress through education: a report submitted to the Executive Council of the Association of American Medical Colleges. Washington DC: Association of American Medical Colleges; 1965.

3. Millis JS. The graduate education of physicians: Report of the Citizens Commission on Graduate Medical Education. Chicago: American Medical Association; 1966.

4. Willard WR. Meeting the challenge of family practice: Report of the Ad Hoc Committee on Education for Family Practice of the Council on Medical Education. Chicago: Council on Medical Education, American Medical Association; 1966.

5. Carnegie Commission on Higher Education. Higher education and the nation's health: policies for medical and dental education. New York: McGraw-Hill; 1970. p. 101-6.

6. US Department of Health and Human Services. Assessment of trends in the education and practice of physicians. Washington DC: US Department of Health and Human Services; 1985

7. Rivo ML, Kindig DA. A report card on the physician work force in the United States. N Engl J Med 1996;334:892-6.

8. Institute of Medicine. A manpower policy for primary care: report of a study. Washington DC: National Academy Press; 1978.

9. Leroy L, Lee P. Deliberations and compromise: The health professions educational assistance act of 1976 . Cambridge (MA): Ballinger Publishing; 1997.

10. Council on Graduate Medical Education. Recommendations to improve access to health care through physician workforce reform: directions for the 21 st century. Rockville (MD): Health Resources and Services Administration, Department of Health and Human Services; 1992. 
11. Donaldson JS, Yordy KD, Lohr KN, Vanselow NA, editors. Primary care: America's health in a new era. Washington DC: National Academy Press; 1996.

12. Aiken LH, Lewis CE, Craig J, Mendenhall RC, Blendon RJ, Rogers DE. The contribution of specialists to the delivery of primary care. $\mathrm{N}$ Engl J Med 1979;300:1363-70.

13. Rosenblatt RA, Hart LG, Baldwin LM, Chan L, Schneeweiss $\mathrm{R}$. The generalist role of specialty physicians: is there a hidden system of primary care? JAMA 1998;279:1364-70.

14. Rosenblatt RA, Cherkin DC, Schneeweiss R, Hart LG. The content of ambulatory medical care in the United States: an interspecialty comparison. N Engl J Med 1983;309:892-7.

15. Rosenblatt RA, Hart LG, Gamliel S, Goldstein B, McClendon BJ. Identifying primary care disciplines by analyzing the diagnostic content of ambulatory care. J Am Board Fam Pract 1995;8:73-5.

16. Forrest CB, Starfield B. Entry into primary care and continuity: the effects of access. Am J Public Health 1998;88:1330-6.

17. American Medical Association. Socioeconomic characteristics of medical practice 1997. Chicago: American Medical Association; 1997.

18. Fryer GE, Vojir CP, Stine C, et al. Personal and educational background predictors of physician practice profiles: the case of Colorado. Eval Program Plann 1998;21:307-14.

19. Harrold LR, Field TS, Gurwitz JH. Knowledge, patterns of care, and outcomes of care for generalists and specialists. J Gen Intern Med 1999;14:499-511.

20. Weingarten SR, Lloyd L, Chiou C, Braunstein GD.
Do subspecialists working outside of their specialty provide less efficient and lower-quality care to hospitalized patients than do primary care physicians? Arch Intern Med 2002;162:527-32.

21. DeVoe J, Fryer GE, Hargraves L, Phillips R, Green L. The association of career dissatisfaction with inability to deliver high quality patient care: the case of family practice/general practice. J Fam Pract 2002; 51:223-38.

22. Ambulatory health care data. US Department of Health and Human Services, Centers for Disease Control and Prevention, National Center for Health Statistics. Available at: URL: http://www.cdc.gov/ nchs/about/major/ahcd/ahcd1.htm.

23. Center for Studying Health System Change. Community Tracking Study Physician Survey, 1996-1997: [United States] [Computer file]. 2nd ICPSR version. Washington DC: Center for Studying Health System Change [producer]; 2001. Ann Arbor (MI): Inter-university Consortium for Political and Social Research; 2001.

24. Race, ethnicity \& medical care: a survey of public perceptions and experiences. Menlo Park (CA): Kaiser Family Foundation; 1999.

25. Puf data files. Rockville (MD): Agency for Healthcare Research and Quality; 2001. Available at: URL: http://www.meps.ahcpr.gov/Puf/DataResultsData. asp? ID $=20$.

26. Green LA, Fryer GE. Family practice in the United States: position and prospects. Acad Med 2002;77: 781-9.

27. Cooper RA. There's a shortage of specialists: is anyone listening? Acad Med 2002;77:761-6. 